\title{
Shifting North American drug markets and challenges for the system of care
}

\author{
R. Michael Krausz ${ }^{1}$, Jean N. Westenberg ${ }^{1,7^{*}}\left(\mathbb{D}\right.$, Nickie Mathew ${ }^{1,2,3}$, George Budd ${ }^{2}$, James S. H. Wong ${ }^{1,2}$, \\ Vivian W. L. Tsang ${ }^{1}$, Marc Voge ${ }^{4,5}$, Conor King ${ }^{6}$, Vijay Seethapathy ${ }^{1,3}$, Kerry Jang ${ }^{1}$ and Fiona Choi ${ }^{1}$
}

\begin{abstract}
Drug markets are dynamic systems which change based on demand, competition, legislation and revenue. Shifts that are not met with immediate and appropriate responses from the healthcare system can lead to public health crises with tragic levels of morbidity and mortality, as experienced Europe in the early 1990s and as is the case in North America currently. The major feature of the current drug market shift in North America is towards highly potent synthetic opioids such as fentanyl and fentanyl analogues. An additional spike in stimulant use further complicates this issue. Without understanding the ever-changing dynamics of drug markets and consequent patterns of drug use, the healthcare system will continue to be ineffective in its response, and morbidity and mortality will continue to increase. Economic perspectives are largely neglected in research and clinical contexts, but better treatment alternatives need to consider the large-scale macroeconomic conditions of drug markets as well as the behavioural economics of individual substance use. It is important for policy makers, health authorities, first responders and medical providers to be aware of the clinical implications of drug market changes in order to best serve people who use drugs. Only with significant clinical research, a comprehensive reorganization of the system of care across all sectors, and an evidence-driven governance, will we be successful in addressing the challenges brought on by the recent shifts in drug markets.
\end{abstract}

Keywords: Drug markets, Drug policy, Fentanyl, Overdose, Public health crisis

\section{Introduction}

Due to the ongoing overdose crisis in Canada and the United States (US), key components in the system of care must be reconsidered, including governance and treatment paradigms. Akin to the HIV pandemic, appalling mortality rates are getting far too little attention and the healthcare system is not responding as needed. Remarkable is the amount of attention and resources going towards the COVID-19 pandemic in comparison to the overdose crisis, despite the fact, that e.g., in British Columbia (BC), the epicenter of the Canadian

\footnotetext{
${ }^{*}$ Correspondence: jwestenb@student.ubc.ca

${ }^{7}$ Addictions and Concurrent Disorders Research Group, Institute of Mental Health, UBC, David Strangway Building, 5950 University Boulevard, Vancouver, BC V6T 1Z3, Canada

Full list of author information is available at the end of the article
}

overdose crisis, the numbers of people dying by overdose was more than $50 \%$ higher in relation to COVID19 in 2020 [1, 2]. Treatment capacity for people who use drugs (PWUD), which was insufficient to begin with, has further decreased to make room for COVID-19 relief. For example, in response to physical distancing protocols, Insite, one of Vancouver's Supervised Consumption Sites (SCS), reduced its capacity from 24 to 6. BC wide, the number of people accessing SCSs dropped by almost $50 \%$, from 853,619 overdose prevention site visits in 2019 to 570,619 in 2020 [3]. Moreover, known triggers for substance use and relapse such as stress and isolation have all increased as a result of the pandemic. This has contributed to increased prevalence or severity of substance use disorders and harms related to substance use $[4,5]$. To worsen an already dire situation, business closures, original author(s) and the source, provide a link to the Creative Commons licence, and indicate if changes were made. The images or other third party material in this article are included in the article's Creative Commons licence, unless indicated otherwise in a credit line to the material. If material is not included in the article's Creative Commons licence and your intended use is not permitted by statutory regulation or exceeds the permitted use, you will need to obtain permission directly from the copyright holder. To view a copy of this licence, visit http://creativecommons.org/licenses/by/4.0/. The Creative Commons Public Domain Dedication waiver (http://creativeco mmons.org/publicdomain/zero/1.0/) applies to the data made available in this article, unless otherwise stated in a credit line to the data. 
border closures, and physical distancing directives have led to changes in the drug markets, accelerating the increased presence of higher potency synthetic opioids such as fentanyl and fentanyl analogues [6].

Health conditions such as high-risk substance use are mainly interpreted as individualized behavioral consequences based on psychological, genetic or biological underpinnings. However, the dynamics of drug markets significantly influence the economic and social factors that frame individual substance use behaviors. It is important to understand the dynamic changes in demand, competition, legislation and revenue of drug markets in order to plan for appropriate health care adaptations or reforms.

\section{Overdose crisis overview}

Between 1999 and 2019, the overdose crisis in North America has been described in three distinct waves (Fig. 1) [7]. The first wave was attributed to the significant increase in the medical prescription of opioids for postoperative use and pain management, which placed the American and Canadian opioid consumption per capita among the highest in the world [8]. This was spurred on by pressures and marketing tactics from large pharmaceutical companies towards physicians in prescribing opioids such as OxyContin $[9,10]$, but also by insufficient "opioid stewardship" spanning legal systems and healthcare systems, most notably pain treatment and substance use treatment. The second wave began in 2010 with a rapid increase in street heroin-related overdoses, while the third wave, which began in 2013, marks the appearance of synthetic opioids and the rise of synthetic opioid-related deaths [7]. These synthetic opioids, such as fentanyl and its analogues, K2/Spice (cannabinoid), and those with cryptic acronyms like $25 \mathrm{i}-\mathrm{NBOMe}$ (hallucinogen), were all originally conceived in legitimate laboratories for proper scientific and therapeutic purposes, but their formulas were then exploited and manufactured. Moreover, to stay ahead of the law, their molecular structures are being consistently altered which make the drugs' effects unpredictable [11, 12]. A potential fourth wave may be gathering force due to increases in stimulant use (especially methamphetamine), entwined with high availability and use of highly potent opioids [13].

\section{Phases of change related to synthetic opioids}

Since the increased spread of synthetic opioids in the third wave of the overdose crisis, the landscape of drug markets in the United States and Canada has gone through several phases, which have continued to exacerbate the public health crisis and overdose related fatalities (Table 1). What began as a traditional drug market with occasional fentanyl use (Phase 0) grew to widespread contamination with imported fentanyl (Phase 1), advancing towards local production of potent opioids

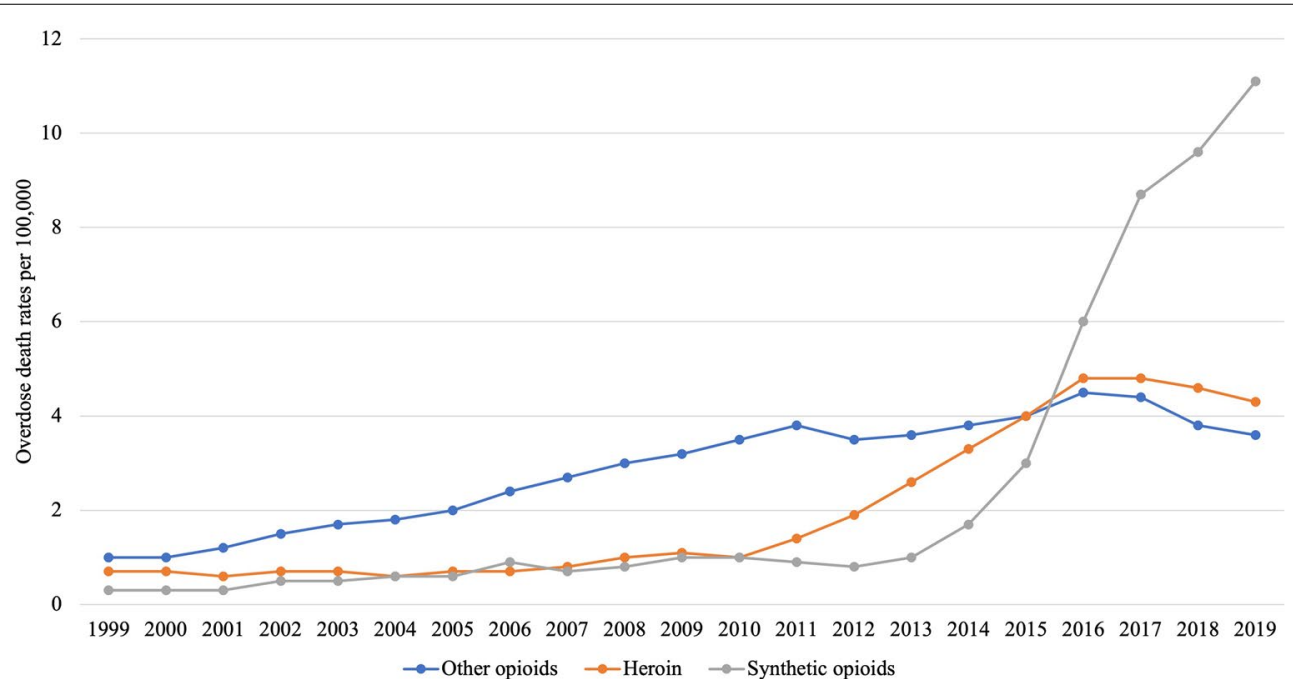

Fig. 1 The three waves of the overdose crisis: opioid overdose deaths by type of opioid. Drug poisoning deaths classified using ICD-10 underlying cause of death codes (X40-X44, X60-X64, X85 and Y10-Y14) and by drugs involved as immediate or contributory causes of death: heroin (T40.1), synthetic opioids, most importantly fentanyl (T40.4) and opioids other than methadone, opium, heroin and synthetic opioids (T40.2). Data accessed from the Centers for Disease Control and Prevention, National Center for Health Statistics. Multiple Cause of Death 1999-2019 on CDC WONDER Online Database, released in 2020. Data are from the Multiple Cause of Death Files, 1999-2019, as compiled from data provided by the 57 vital statistics jurisdictions through the Vital Statistics Cooperative Program. Accessed at http://wonder.cdc.gov/mcd-icd10.html on Nov 21, 2021 2:55:14 PM 
Table 1 The phases of development in the North American drug market related to fentanyl use

\begin{tabular}{|c|c|c|c|c|}
\hline Phase & Timeline & Significant features & Overdose & Outcomes \\
\hline $\begin{array}{l}\text { 0_traditional drug market: } \\
\text { occasional fentanyl use }\end{array}$ & Before 2013 & $\begin{array}{l}\text { Repurposing of fentanyl } \\
\text { patches; fentanyl use in small } \\
\text { groups }\end{array}$ & $\begin{array}{l}\text { Occasional fentanyl-related } \\
\text { overdose deaths }\end{array}$ & Local problems \\
\hline $\begin{array}{l}1 \text {-growing market: contami- } \\
\text { nation of street drugs }\end{array}$ & 2013-2018 & $\begin{array}{l}\text { Import of fentanyl from Asia to } \\
\text { North America and Mexico }\end{array}$ & $\begin{array}{l}\text { Significant increase in overdose } \\
\text { deaths; synthetic opioids } \\
\text { surpass heroin and prescription } \\
\text { opioids }\end{array}$ & $\begin{array}{l}\text { Regional problems, especially } \\
\text { West Coast of Canada }\end{array}$ \\
\hline $\begin{array}{l}\text { 2-developed market: locally } \\
\text { produced fentanyl }\end{array}$ & 2019 to present & $\begin{array}{l}\text { Interruption of overseas fenta- } \\
\text { nyl import; precursor import } \\
\text { and local fentanyl production; } \\
\text { additional COVID-19 impacts }\end{array}$ & $\begin{array}{l}\text { Historically high numbers of } \\
\text { opioid overdose deaths; almost } \\
\text { exclusive fentanyl-related }\end{array}$ & $\begin{array}{l}\text { High availability of fentanyl; new } \\
\text { routes of application; intentional } \\
\text { fentanyl use }\end{array}$ \\
\hline
\end{tabular}

and omnipresence of fentanyl in the drug market (Phase 2).

\section{Phase 0_"traditional" drug market (before 2013)}

Introduction of fentanyl into the drug market started as a small phenomenon related to the diversion of fentanyl patches, before organized importation of highly potent synthetic opioids began in North America and Mexico $[14,15]$. This continues to be the present reality of most European countries which are not experiencing the same widespread fentanyl use and increase of drug overdoses compared to North America [16-18].

There were also a few isolated large-scale illicit fentanyl laboratories in operation. For example, one located in Toluca, Mexico had been in operation for several years and has been linked to a surge in overdose deaths between 2005 and 2007 in the Mid-West of the United States [19]. This specific laboratory was eventually shut down by Mexican Authorities in 2007, and was surprisingly not immediately replaced by another. Illicit fentanyl production was mostly halted across North America, with China emerging as a source country.

\section{Phase 1-contamination of street drugs in a mixed market (2013-2018)}

Several factors lead to fentanyl's increasing prevalence in the drug market, which was being almost exclusively imported from China [20]. The most important advantage of fentanyl is its potency, approximately 70 times more potent in depressing respiratory rate that of heroin or morphine [21]. Less fentanyl is needed to attain "euphorigenic" effects, which greatly benefitted traffickers due to the lowered risk of interception by authorities. Another advantage of fentanyl was its synthetic nature, allowing for eventual streamlining of laboratory production and lower price of overall production. Fentanyl was therefore systematically mixed or "cut" with heroin, and dealers were able to sell greater amounts of so-called "heroin" for higher profits [20]. This eventually became the standard business model. At the time, most users were not aware of the presence of fentanyl, which resulted in consecutive overdose experiences among PWUD [22, 23]. In Canada, various Organized Crime Groups (OCG) were and are responsible for fentanyl importation from China and distribution within the country, starting in British Columbia and moving towards the East. In the US, Mexican cartels have played a similar role.

The contamination of the drug supply was reflected in substance use patterns and drug seeking behaviors. Changes in demand were reported from traditional heroin seekers to individuals who used mixed opioids (heroin and fentanyl) and individuals who used fentanyl primarily [24]. The routes of administrations also diversified from patches and tablets to injection, utilizing athome "cooking" techniques to convert oral tablets into liquids for intravenous use. Inhaling also became an important route of administration, especially in the BC market, creating an illusion of safety for users because of the pharmacokinetic parameters of inhalation, including lower peak plasma concentrations relative to injection [25]. This method of administration makes it more attractive to new users especially, who prefer to not inject for various reasons. Nevertheless, the BC Coroner Service report that among all overdoses fatalities, deaths related to inhaling climbed from $28.3 \%$ in 2016 to $40.8 \%$ in 2017 , and remain above $40 \%$ to this day [26].

Nevertheless, fentanyl gradually took over the drug market. The Drug Enforcement Agency (DEA) and the Canadian Border Service Agency both reported substantial increases in seizures of illicitly manufactured fentanyl [27, 28]. For instance, in the United States, the total number of fentanyl reports submitted to forensic laboratories increased by 65\% from 2016 to 2017 [28]. As the level of fentanyl in the drug markets gradually 
increased from 2013 to 2018, so did opioid-related overdose fatalities [29].

\section{Phase 2-omnipresence of fentanyl in the drug market} Fentanyl-containing products, which was mostly localized and distributed in patches across North America up until 2019, then became omnipresent. Contaminated street drugs that were laced with fentanyl gave way to new market trends, including PWUD desiring pure fentanyl. Given fentanyl's increasing influence in the drug market, policy responses attempted to address the prolific international fentanyl trafficking networks.

\section{Phase 2a-legal action in China against fentanyl production and exportation (2019)}

In May 2019, China prohibited the production, sale and exportation of all fentanyl class-drugs except for some authorized firms which the Chinese government granted special licenses [30]. The influx of fentanyl from China to North America noticeably declined. Canadian Customs and Border Protection reported that seizures of fentanyl directly shipped from China dropped from over $116 \mathrm{~kg}$ in 2017 to less than $200 \mathrm{~g}$ in 2019 [30].

\section{Phase $2 \mathrm{~b}$-import of precursors from Asia to Mexico and British Columbia (2019 to present)}

The interruption of the fentanyl supply led to an adaption in production and supply strategies. As a result of China's class scheduling of fentanyl, precursors in the production of fentanyl-like opioids, which did not fall under restrictions, began being traded. Precursors like $\mathrm{N}$-Phenethyl-4-piperidinone (NPP) and 4-anilino-Nphenethylpiperidine (4-ANPP) are both used as intermediates in the synthesis of fentanyl. After production of these precursors in Asia and exportation to North America and Mexico, they were then used for fentanyl local production. International regulations then banned the two primary precursors, NPP and 4-ANPP, but alternate precursors began being produced and shipped [30].

\section{Phase 2c-trading through Mexico (2019 to present)}

Using imported precursors from China, Mexican TransNational Criminal Organizations (TCO), primarily the Sinaloa Cartel and the Jalisco New Generation Cartel, are able to produce immense volumes of high-grade fentanyl. The production and subsequent distribution of their fentanyl utilizes established laboratories and trading routes already used for other substances. The fentanyl is bundled in large quantities and smuggled across the Southwest Border, often with shipments that also contain bundles of Mexican heroin and Columbian cocaine. The bundles are distributed across the US by regional drug trafficking groups and street gangs who will then adulterate the fentanyl with cutting agents to increase the volume, or mix it with other illicit drugs, before it reaches end users [28].

\section{Phase 2d-trading through British Columbia (2019 to present)}

As the importation and availability of fentanyl decreased because of the ban introduced by the Chinese Government, Canadian OCGs, primarily in British Columbia, turned to the domestic production of fentanyl. Though laboratories had been heavily involved in the production of methamphetamine, operations have been repurposed and capacity has been augmented for local fentanyl production, utilizing drug synthesis knowledge, laboratory equipment and clandestine locations previously employed in methamphetamine production [31].

Domestic production has resulted in a much greater availability of fentanyl on the drug market, as the volume of fentanyl produced per laboratory in $\mathrm{BC}$ is known to be much more than the volume imported from overseas. For instance, the Royal Canadian Mountain Police (RCMP) located a large illicit drug-manufacturing site in Surrey, BC in early May 2021, containing $37 \mathrm{~kg}$ of chemicals associated with fentanyl production, with a potential estimated finished yield of $26 \mathrm{~kg}$ of pure fentanyl per week [32]. In the year prior, between 2020 and 2021, the Canadian Border Services Agency report having seized roughly $7.4 \mathrm{~kg}$ of fentanyl [33]. As a result of this increased availability, OCG and those within the distribution network, from street gangs to individual actors, do not need to adulterate the fentanyl to the same degree as was necessary previously, when the only source was China and the volume available was much lower. This results in much greater purity (close to $85 \%$ ) when compared to the pre-domestic production period, though the potency has remained similar. PWUD are therefore consuming much purer fentanyl, and this has been reflected in post-mortem toxicology screens. In the past year, approximately $13 \%$ of overdose deaths had extreme fentanyl concentrations (exceeding $50 \mu \mathrm{g} /$ litre), as compared to $8 \%$ a year prior [1]. Moreover, carfentanil, an elephant tranquilizer about 10,000 times more potent than morphine and 30-100 times more potent than fentanyl, has been detected in 113 overdoses in the first 6 months of 2021, already far exceeding the 2020 total of 65 [1].

\section{Clinical consequences}

The changes of the drug market in US and Canada have led to a significant shift in patterns of use and a dramatic increase in drug overdose cases and fatalities, especially in $\mathrm{BC}$ [1]. The situation is not currently identical in all regions of North America, with provinces such as British Columbia and Alberta as well as states such as California 
and Florida experiencing the highest number of overdose deaths in Canada and the United States respectively [35]. Nevertheless, the changing landscape of synthetic opioid use has led to changes both in clinical observations and considered interventions when treating patients for overdoses or harm reduction through opioid agonist treatment (OAT). It is important for policy makers, health authorities, first responders and medical providers to be aware of the clinical implications of the changes in the drug market in order to best serve PWUD.

\section{Increasing significance of fentanyl}

Fentanyl and its derivates have gained an immense importance in North America. Before 2012, there was only sporadic use of fentanyl in different parts of the world, including Europe. Cooking fentanyl patches and injecting the fluid was rare, and led to multiple fatalities in Munich, Germany [36]. Injection or inhalation of fentanyl was not widespread, and the use of contaminated street drugs was unintentional in the beginning. In North America, this pattern of use has now changed towards intentional use of fentanyl and fentanyl-seeking behaviors. Fentanyl has become dominant based mainly on four factors: cheaper price, increased availability, high potency, and very intense onset with a short intoxication period, relative to other opioids [37]. For instance, fentanyl's price and availability has made it more attractive to inhale, which has increased its use among to diverse groups of PWUD, not only PWID.

\section{Fentanyl as drug of choice}

Drug checking to identify fentanyl in street drugs and avoid its consumption is something of the past. Today, a growing number of PWUD utilize drug checking services to find fentanyl, which has become the drug of choice for some $[38,39]$. A main reason for the shift from unintentional to intentional fentanyl use may be an attempt to regain control. Many PWUD have been exposed to unintentional fentanyl use over the last couple of years, which has resulted in an increase in tolerance, thereby making it difficult for PWUD to continue using less-potent opioids such as heroin or oral medications such as oxycontin [24]. The high tolerance in current PWUD means that individuals are forced to seek higher potency opioids, now only found in fentanyl and fentanyl derivatives. For example, a pattern of use largely seen between 2016 and 2019 was the mixing of intravenous heroin with fentanyl, also called 'fentanyl with legs' as the heroin kicks in while the rush of fentanyl fades away. However, this practice has waned as heroin is increasingly difficult to find at the street level. There is also an increase in mixing fentanyl with sedatives, including benzodiazepines like alprazolam and diazepam, and chemically related drugs like etizolam, in order to similarly provide "legs" to the fentanyl. Responding to mixed fentanyl-benzodiazepine overdoses is a complex, challenging medical intervention dealing with two classes of drugs simultaneously [40].

Moreover, though patterns of use are driven by neurobiological mechanisms and market forces, they are also based on individual decision-making, personal responsibility, and choice, limited as they may be in such circumstances. For instance, from an individualistic perspective, one's risk of overdose may be in fact more manageable if one seeks fentanyl, since seeking pure heroin within a market contaminated by high potent opioids may make it almost impossible to appropriately manage one's risk of overdose. These are aspects that are to a large degree ignored in research and clinical contexts, despite being important considerations for the development of effective interventions. To provide better alternatives, an effective strategy needs to also include microeconomic and behavioural economic analyses of individual substance use, which there is a paucity of research on $[41,42]$.

\section{Inappropriate and insufficient medical care}

Adverse events related to fentanyl use (e.g., seizures and overdoses) happen on a regular basis and are leading to skyrocketing numbers of emergency calls (over 27,000 in BC in 2020) [43]. In acute care settings, patients with intravenous fentanyl use face the problem of quick and intense withdrawal because the treatment protocols are not adapted to their needs [44-47]. Many of these patients' opioid tolerance is too high for routine OAT options such as methadone, morphine, and breakthrough medications such as hydromorphone [48, 49]. Current hospitals mainly use transdermal formulations of fentanyl and inpatient populations are not routinely prescribed intravenous OAT such as heroin-assisted therapy, which is currently regulated in 8 European countries and Canada and has been proven more clinically effective and cost-effective than oral methadone for this target group [50, 51]. Consequently, many patients facing unbearable withdrawal leave against medical advice despite untreated physical illness [52, 53].

\section{Stimulants in the developed market}

Stimulants (i.e., methamphetamine) continues to be among the most prevalent substances in the American and Canadian illicit drug market [31]. Methamphetamine use has increased significantly among people with an existing opioid use disorder, and there have been significant increases in drug combinations of fentanyl with methamphetamine and cocaine $[54,55]$. It is highly possible that as stimulants and depressants are often used in tandem, the arrival of potent opioids like fentanyl has necessitated increasingly potent stimulants through 
importation and distribution [31]. Recent findings have suggested a potential fourth wave of high mortality may be gathering force in North America involving methamphetamine and cocaine, which may be a new determinant in the ongoing public health crisis [13]. Though stimulant use has been prevalent, treatment options have never truly been available and needs related to stimulant use never been appropriately addressed [56]. There is a need to recognize the explosion in methamphetamine and cocaine related mortalities, and to develop necessary treatment options for stimulant withdrawal and crisis management which are further complicated by fentanyl and high potent opioids [1].

\section{Discussion}

Drug markets are similar to other internationally organized markets. They follow the rules of supply and demand to optimize revenue. The introduction of highly potent opioids has followed these economic principles, with fentanyl and its derivatives outperforming heroin and prescription opioids in North America. For now, the main substance of choice is fentanyl, but this may change again depending on how it will address the risk/revenue ratio.

Addressing a public health crisis requires effective evidence-based healthcare governance and an amalgamation of necessary structures and resources. The experiences with the COVID-19 pandemic provide great learning opportunities for what to avoid and what works, like the benefit of using innovative technologies, investments in new interventions (e.g., COVID-19 vaccine) and the organization of a coherent clinical trajectory.

Finding solutions to the current wave of the overdose crisis requires significant clinical research. For instance, we know little about the user perspective. This would be essential knowledge to enable successful engagement in care and appropriate early intervention. Another topic is the effective response of the healthcare system. How can a treatment be effectively provided and how can appropriate psychosocial and pharmacological approaches be improved and adapted to new challenges? Would free access to psychotropic substances, including high potent opioids, decrease mortality and reduce harm? [58, 59]. Is the unsupervised distribution of high potent psychotropic substances, such as hydromorphone or prescription stimulants, an additional risk? The concept of fentanyl-assisted treatment, analogous to heroin-assisted treatment, has been gaining traction among clinical and academic forums, and large scale clinical research efforts exploring such pragmatic approaches are an immediate priority [60].

In the coming months and possibly years, three main scenarios are to be considered. The first scenario (worst-case) would be the dominance of high potent opioids with a system of care unable to respond. This would inevitably lead to further increases in overdose related mortality. A second scenario (better) would be a slowing down of overdose mortality rates, based on some effective health care measures such as rapid access to quality OAT treatment with high potent opioids like heroin-assisted treatment, universal access to supervised consumption sites, and universal access to psychosocial treatments for anybody at high-risk of overdose or suicide $[61,62]$. Such an integrated clinical trajectory would need substantial changes from the current course of action. The third scenario (best) would be having the healthcare system and decision makers addressing the shift in the drug markets with a response comparable to that used during the HIV pandemic. This would include a critical reconsideration of all components involved in the current approach to substance use care, including the legal framework (e.g., decriminalization of use), a structure for continuity of care, and building non-existent components like prevention, early intervention, youth specific systems.

\section{Conclusions}

We are experiencing a historic shift in the North American drug markets towards highly potent synthetic opioids. Fentanyl and fentanyl analogues are available in different forms, mixed into the street supply or consumed directly as the preferred drug of choice, and are leading to a dramatic increase in mortality across the continent. Research efforts must direct more focus towards the macroeconomic conditions of the drug market and the microeconomics of individual substance use, which are critical to the planning and development of appropriate treatments, services and resources. The only way to stop this is with significant efforts to create comprehensive systems of prevention and treatment, using innovative measures of intervention and immediate accessibility.

\footnotetext{
Abbreviations

HIV: Human immunodeficiency virus; COVID-19: Coronavirus disease of 2019; PWUD: People who use drugs; SCS: Supervised consumption sites; OCG: Organized crime groups; DEA: Drug enforcement agency; OAT: Opioid agonist treatment; US: United States; BC: British Columbia.

\section{Acknowledgements}

JNW is supported by the University of British Columbia Institute of Mental Health Marshall Scholarship Award.

\section{Authors' contributions}

RMK: conceptualization; project administration; supervision; validation; visualization; writing — original draft; writing — review and editing. JNW: conceptualization; project administration; writing —original draft; writing — review and editing. NM: validation, visualization, writing - review and editing. GB: validation; visualization; writing — review and editing. JSHW: conceptualization; validation; visualization; writing —original draft; writing-review and editing. VWLT: conceptualization; validation; visualization; writing —original draft;
} 
writing — review and editing. MV: validation; visualization; writing — review and editing. CK: investigation; validation; visualization; writing_original draft; writing — review and editing. VS: validation; visualization; writing — review and editing. KJ: validation; visualization; writing —review and editing. FC: conceptualization; methodology; supervision; validation; visualization; writing - original draft; writing - review and editing. All authors read and approved the final manuscript.

\section{Funding}

This research did not receive any specific Grant from funding agencies in the public, commercial, or not-for-profit sectors.

\section{Availability of data and materials}

N/A

\section{Declarations}

\section{Ethics approval and consent to participate}

N/A.

\section{Consent for publication}

N/A.

\section{Competing interests}

MV declares research grant from Novartis, and consulting fees from Camurus. All other authors have no competing interests to declare.

\section{Author details}

'Department of Psychiatry, Faculty of Medicine, University of British Columbia, Vancouver, BC, Canada. ${ }^{2}$ Complex Pain and Addiction Service, Vancouver General Hospital, Vancouver, BC, Canada. ${ }^{3}$ BC Mental Health \& Substance Use Services, Provincial Health Services Authority, Vancouver, BC, Canada. ${ }^{4}$ University of Basel Psychiatric Clinics, Basel, Switzerland. ${ }^{5}$ Division of Substance Use Disorders, Psychiatric Services of Thurgovia, Münsterlingen, Switzerland. ${ }^{6}$ Victoria Police Department, Victoria, BC, Canada. ${ }^{7}$ Addictions and Concurrent Disorders Research Group, Institute of Mental Health, UBC, David Strangway Building, 5950 University Boulevard, Vancouver, BC V6T 1Z3, Canada.

\section{Received: 12 October 2021 Accepted: 9 December 2021}

Published online: 20 December 2021

\section{References}

1. BC Coroners Service. Illicit drug toxicity deaths in BC: January 1st, 2011-July 31st, 2021. 2021;21. https://www2.gov.bc.ca/assets/gov/ birth-adoption-death-marriage-and-divorce/deaths/coroners-service/ statistical/illicit-drug.pdf. Accessed 23 Nov 2021.

2. BC Centre for Disease Control. BC COVID-19 data. Provincial Health Services Authority. 2020. http://www.bccdc.ca/health-info/diseases-condi tions/covid-19/data. Accessed 23 Nov 2021.

3. BC Centre for Disease Control. Overdose prevention services indicators. Overdose response indicators. Vancouver: BCCDC; 2021

4. Baillargeon J, Polychronopoulou E, Kuo Y-F, Raji MA. The impact of substance use disorder on COVID-19 outcomes. Psychiatr Serv. 2021;72(5):578-81.

5. Armitage R, Nellums LB. Substance misuse during COVID-19: protecting people who use drugs. Public Health. 2020;183:63.

6. Canadian Centre on Substance Use and Addiction. Impacts of the COVID-19 pandemic on people who use substances: what we heard. 2020. https://www.ccsa.ca/sites/default/files/2020-07/CCSA-COVID19-Impacts-on-People-Who-Use-Substances-Report-2020-en.pdf. Accessed 23 Nov 2021

7. Ciccarone D. The triple wave epidemic: supply and demand drivers of the US opioid overdose crisis. Int J Drug Policy. 2019. https://doi.org/ 10.1016/j.drugpo.2019.01.010.

8. International Narcotics Control Board. Narcotic Drugs Technical Report 2019. New York, NY. 2020. https://www.incb.org/incb/en/narcotic-drugs/ Technical_Reports/2019/narcotic-drugs-technical-report-2019.html. Accessed 23 Nov 2021.
9. Larochelle MR, Zhang F, Ross-Degnan D, Wharam JF. Rates of opioid dispensing and overdose after introduction of abuse-deterrent extendedrelease oxycodone and withdrawal of propoxyphene. JAMA Intern Med. 2015;175(6):978-87.

10. Cicero TJ, Inciardi JA, Muñoz A. Trends in abuse of OxyContin ${ }^{\circledR}$ and other opioid analgesics in the United States: 2002-2004. J Pain. 2005:6(10):662-72.

11. Alves VL, Gonçalves JL, Aguiar J, Teixeira HM, Câmara JS. The synthetic cannabinoids phenomenon: from structure to toxicological properties. A review. Crit Rev Toxicol. 2020;50(5):359-82.

12. Ovenden SPB, McDowall LJ, McKeown HE, McGill NW, Jones OAH, Pearson JR, et al. Investigating the chemical impurity profiles of fentanyl preparations and precursors to identify chemical attribution signatures for synthetic method attribution. Forensic Sci Int. 2021;321:110742.

13. Ciccarone D. The rise of illicit fentanyls, stimulants and the fourth wave of the opioid overdose crisis. Curr Opin Psychiatry. 2021. https://doi.org/10. 1097/YCO.0000000000000717.

14. Woodall KL, Martin TL, McLellan BA. Oral abuse of fentanyl patches (Duragesic $^{\circledR}$ ): seven case reports. J Forensic Sci. 2008;53(1):222-5.

15. Lilleng PK, Mehlum LI, Bachs L, Morild I. Deaths after intravenous misuse of transdermal fentanyl. J Forensic Sci. 2004;49(6):JFS2004143-3.

16. Krausz RM, Westenberg JN, Ziafat K. The opioid overdose crisis as a global health challenge. Curr Opin Psychiatry. 2021. https://doi.org/10.1097/ YCO.0000000000000712.

17. Alho H, Dematteis M, Lembo D, Maremmani I, Roncero C, Somaini L. Opioid-related deaths in Europe: strategies for a comprehensive approach to address a major public health concern. Int J Drug Policy. 2020;76:102616.

18. European Monitoring Centre for Drugs and Drug Addiction. European Drug Report. European Union Publications Office. 2019. http://www. emcdda.europa.eu/system/files/publications/4541/TDAT17001ENN.pdf_ en. Accessed 23 Nov 2021.

19. Denton JS, Donoghue ER, McReynolds J, Kalelkar MB. An epidemic of illicit fentanyl deaths in Cook County, Illinois: September 2005 through April 2007. J Forensic Sci. 2008;53(2):452-4.

20. O'Connor S. Fentanyl: China's deadly export to the United States. Washington: US-China Economic and Security Review Commission; 2017.

21. Hill R, Santhakumar R, Dewey W, Kelly E, Henderson G. Fentanyl depression of respiration: comparison with heroin and morphine. Br J Pharmacol. 2020;177(2):254-65.

22. Carroll JJ, Marshall BDL, Rich JD, Green TC. Exposure to fentanyl-contaminated heroin and overdose risk among illicit opioid users in Rhode Island: a mixed methods study. Int J Drug Policy. 2017:46:136-45.

23. Mars SG, Ondocsin J, Ciccarone D. Sold as heroin: perceptions and use of an evolving drug in Baltimore, MD. J Psychoact Drugs. 2018;50(2):167-76.

24. Mathew N, Wong JSH, Krausz RM. An inside look at BC's illicit drug market during the COVID-19 pandemic. BC Med J. 2021;63:9-13.

25. Rook EJ, Van Ree JM, Van Den Brink W, Hillebrand MJX, Huitema ADR, Hendriks VM, et al. Pharmacokinetics and pharmacodynamics of high doses of pharmaceutically prepared heroin, by intravenous or by inhalation route in opioid-dependent patients. Basic Clin Pharmacol Toxicol. 2006:98(1):86-96.

26. BC Coroners Service. Knowledge update: mode of consumption. 2020. https://www2.gov.bc.ca/assets/gov/birth-adoption-death-marriage-anddivorce/deaths/coroners-service/statistical/illicit-drug.pdf. Accessed 23 Nov 2021.

27. Payer DE, Young MM, Maloney-Hall B, Mill C, Leclerc P, Buxton J, et al. Adulterants, contaminants and co-occurring substances in drugs on the illegal market in Canada. Ottawa: Canadian Centre on Substance Use and Addiction; 2020.

28. Drug Enforcement Administration. National drug threat assessment. Arlington: Drug Enforcement Administration Strategic Intelligence Section, US Department of Justice; 2019. p. 2001-20.

29. Zibbell JE, Aldridge AP, Cauchon D, DeFiore-Hyrmer J, Conway KP. Association of law enforcement seizures of heroin, fentanyl, and carfentanil with opioid overdose deaths in Ohio, 2014-2017. JAMA Netw Open. 2019;2(11):e1914666-e1914666. https://doi.org/10.1001/jamanetwor kopen.2019.14666.

30. Congressional Research Service. Illicit fentanyl and China's role. Washington: Congressional Research Service; 2021.

31. Canadian Integrated Response to Organized Crime. Closing in on meth: The Canadian Enforcement Strategy (2020-2021). 2020. https://www. 
multibriefs.com/briefs/cacp/National\%20Methamphetamine\%20Str ategy\%20-\%20English\%20(Jan2020)\%20(004).pdf. Accessed 23 Nov 2021.

32. Royal Canadian Mountain Police. Massive drug lab bust highlights coordinated approach to gangs and organized crime. Newsroom. Surrey, BC. 2021. https://bc-cb.rcmp-grc.gc.ca/ViewPage.action?siteNodeld=2126\& languageld=1\&contentld=69480. Accessed 2 Jun 2021.

33. Canada Border Services Agency. Canada Border Services Agency seizures. Securing the border. 2021. https://www.cbsa-asfc.gc.ca/security-securite/ seizure-saisie-eng.html. Accessed 30 Jun 2021.

34. Centers for Disease Control and Prevention. 2019 drug overdose death rates. 2021. https://www.cdc.gov/drugoverdose/data/statedeaths/drugoverdose-death-2019.html. Accessed 9 Jun 2021.

35. Opioid Overdose Surveillance Task Group of the Special Advisory Committee on the Epidemic of Opioid Overdoses. Apparent opioid and stimulant toxicity deaths. Ottawa: PHAC; 2021.

36. Sinicina I, Sachs $H$, Keil W. Post-mortem review of fentanyl-related overdose deaths among identified drug users in Southern Bavaria, Germany, 2005-2014. Drug Alcohol Depend. 2017;180:286-91.

37. Martinez S, Jones JD, Brandt L, Campbell ANC, Abbott R, Comer SD. The increasing prevalence of fentanyl: a urinalysis-based study among individuals with opioid use disorder in New York City. Am J Addict. 2020 https://doi.org/10.1111/ajad.13092.

38. Morales KB, Park JN, Glick JL, Rouhani S, Green TC, Sherman SG. Preference for drugs containing fentanyl from a cross-sectional survey of people who use illicit opioids in three United States cities. Drug Alcohol Depend. 2019;204(107547):1-8.

39. Misailidi N, Papoutsis I, Nikolaou P, Dona A, Spiliopoulou C, Athanaselis S. Fentanyls continue to replace heroin in the drug arena: the cases of ocfentanil and carfentanil. Forensic Toxicol. 2018;36(1):12-32. https://doi. org/10.1007/s11419-017-0379-4.

40. Purssell R, Buxton JA, Godwin J, Moe J. Potent sedatives in opioids in BC implications for resuscitation, and benzodiazepine and etizolam withdrawal. BC Med J. 2021;63(4):177-8.

41. Lenoir M, Ahmed SH. Supply of a nondrug substitute reduces escalated heroin consumption. Neuropsychopharmacology. 2008;33(9):2272-82.

42. Greenwald MK, Hursh SR. Behavioral economic analysis of opioid consumption in heroin-dependent individuals: effects of unit price and pre-session drug supply. Drug Alcohol Depend. 2006;85(1):35-48.

43. BC Emergency Health Services. Overdose response in BC Communities. 2021. http://www.bcehs.ca/health-info-site/Documents/OverdoseRe sponseinBCCommunitiesPDF.pdf. Accessed 23 Nov 2021.

44. Silverstein SM, Daniulaityte R, Martins SS, Miller SC, Carlson RG. "Everything is not right anymore": buprenorphine experiences in an era of illicit fentanyl. Int J Drug Policy. 2019;74:76-83.

45. Merchant E, Burke D, Shaw L, Tookes H, Patil D, Barocas JA, et al. Hospitalization outcomes of people who use drugs: one size does not fit all. J Subst Abuse Treat. 2020;112:23-8.

46. Neimark G, Tjoa C. Treating fentanyl withdrawal. J Behav Health Serv Res. 2020:47(4):614-5.

47. Bohnert ASB, Lin LA. It is time to recognize that synthetic opioids are not going away. Addiction. 2021;116:1313-8.

48. Moe J, Godwin J, Purssell R, O'Sullivan F, Hau JP, Purssell E, et al. Naloxone dosing in the era of ultra-potent opioid overdoses: a systematic review. Can J Emerg Med. 2020;22(2):178-86.

49. Antoine D, Huhn AS, Strain EC, Turner G, Jardot J, Hammond AS, et al. Method for successfully inducting individuals who use illicit fentanyl onto buprenorphine/naloxone. Am J Addict. 2021;30(1):83-7.

50. Ferri M, Davoli M, Perucci CA. Heroin maintenance for chronic heroindependent individuals. Cochrane Database Syst Rev. 2010. https://doi. org/10.1002/14651858.CD003410.pub3.

51. Boyd S, Murray D, MacPherson D. Telling our stories: heroin-assisted treatment and SNAP activism in the Downtown Eastside of Vancouver. Harm Reduct J. 2017;14(1):1-14.

52. Moreno JL, Wakeman SE, Duprey MS, Roberts RJ, Jacobson JS, Devlin JW. Predictors for 30-Day and 90-day hospital readmission among patients with opioid use disorder. J Addict Med. 2019. https://doi.org/10.1097/ ADM.0000000000000499.

53. Ti L, Ti L. Leaving the hospital against medical advice among people who use illicit drugs: a systematic review. Am J Public Health. 2015;105(12):e53-9.
54. Ellis MS, Kasper ZA, Cicero TJ. Twin epidemics: the surging rise of methamphetamine use in chronic opioid users. Drug Alcohol Depend. 2018:193:14-20.

55. Niles JK, Gudin J, Radcliff J, Kaufman HW. The opioid epidemic within the COVID-19 pandemic: drug testing in 2020. Popul Health Manag. 2021;24(S1):S-43.

56. Ronsley C, Nolan S, Knight R, Hayashi K, Klimas J, Walley A, et al. Treatment of stimulant use disorder: a systematic review of reviews. PLOS ONE. 2020;15(6):1-22. https://doi.org/10.1371/journal.pone.0234809.

57. Hedegaard H, Miniño AM, Warner M. Drug overdose deaths in the United States, 1999-2019. NCHS data brief. Hyattsville, MD. 2020. https://www. cdc.gov/nchs/data/databriefs/db394-H.pdf. Accessed 23 Nov 2021.

58. Krausz RM, Wong JSH, Westenberg JN, Choi F, Schütz CG, Jang KL. Canada's response to the dual public health crises: a cautionary tale. Can J Psychiatry. 2021. https://doi.org/10.1177/0706743721993634.

59. British Columbia Centre on Substance Use. Risk mitigation: in the context of dual public health emergencies. Vancouver: British Columbia Centre on Substance Use; 2020

60. Krausz RM, Westenberg JN, Vogel M. Addressing fentanyl use disorder with fentanyl-assisted treatment? Lancet Psychiatry. 2021. https://doi.org/ 10.1016/s2215-0366(21)00393-x

61. Liebrenz M, Gamma A, Buadze A, Schleifer R, Baggio S, Schwartz B, et al. Fifteen years of heroin-assisted treatment in a Swiss prison-a retrospective cohort study. Harm Reduct J. 2020;17(1):1-8.

62. Oviedo-Joekes E, Nosyk B, Brissette S, Chettiar J, Schneeberger P, Marsh DC, et al. The North American Opiate Medication Initiative (NAOMI): profile of participants in North America's first trial of heroin-assisted treatment. J Urban Heal. 2008;85(6):812-25.

\section{Publisher's Note}

Springer Nature remains neutral with regard to jurisdictional claims in published maps and institutional affiliations.

Ready to submit your research? Choose BMC and benefit from

- fast, convenient online submission

- thorough peer review by experienced researchers in your field

- rapid publication on acceptance

- support for research data, including large and complex data types

- gold Open Access which fosters wider collaboration and increased citations

- maximum visibility for your research: over 100M website views per year

At BMC, research is always in progress.

Learn more biomedcentral.com/submissions 